\title{
A Study on the Design of Hot Spring Health Landscape in Panzhihua
}

\author{
Jian Cao \\ Art College \\ Panzhihua University \\ Panzhihua, China 617000
}

\begin{abstract}
With the proposal of the name card of health city of Panzhihua, the continuous development, construction and landscape design of hot spring health are attracting more and more attention. Hongge Hot Springs as a name card of Panzhihua to create a health city, its status is becoming increasingly important. The purpose of this paper is to explore how to use the existing tourism resources to inherit the local regional nationalities, convey the culture of the city and realize the purposes of industrialization and urban transformation mainly through the study on the design of health landscape of Hongge Hot Springs in Panzhihua.
\end{abstract}

Keywords-landscape design; hot spring health; culture; transformation

\section{INTRODUCTION}

Panxi area is located in Yunnan and Sichuan geothermal area, one of the four major geothermal areas in China, with rich geothermal resources, and many hot spring flow-out points. With the enthusiasm of developers on hot spring tourism, as well as the policy support from government for investment enterprises, the number of hot spring resorts in Panxi is increasing, and the scale is gradually becoming larger. The comprehensive quality of the hot spring resources in Panxi is higher than others, of which the temperature is at medium and low temperature suitable for human body. It is rich in a variety of minerals and trace elements beneficial to the human body. There are not only the type of common hot springs of bicarbonate, sulfuric acid, and chloride, but also the types of rare elements such as oxygen and bittern. The radon hot springs that are special to Hongge have the scarcity of resource development, which are easy to form characteristic brand products, and provide favorable conditions for the diversification of hot spring products. We should follow the development concept of "sunshine, sports, and leisure" , make full use of the existing hot spring hotels, sports bases, conference centers, resort hotels and other leisure facilities taking the opportunity of creating "China sunshine health tourism city" in Panzhihua and actively promote the construction of national sports industry development zone (including comprehensive sports winter training base, orchard sports base, equipping with sports health center, high-level medical service facilities, etc.), Xinminxi tourism community, international dynamic hot spring experience museum, international conference holiday center, new tourism community for aged from different places and other projects, to build it into a core project zone of "Sunshine flower city health resort" in Panzhihua and pilot area for industrial transformation and development.

\section{A StUdy ON THE Health StRATEGy OF HONGGE HOT SPRINGS}

As the hot spring consumers become more and more mature, development of hot spring tourism needs the hot spring tourism products with differentiation. The author grasps the development trend of hot spring tourism, takes the development road of "hot spring + " product, which integrates health and leisure needed by modern people into the life and work, and highlight the characteristics of hot spring tourism products through the integration and innovation of cultural themes. The author designs the hot springs health strategies including hot springs + sports health, hot springs + health care for the elderly, hot spring + ecological heart nourishing, and hot springs + cultural experience according to the hot spring resources and the needs of Panzhihua, to explore the hot spring market, and achieve the optimization and upgrading of hot spring tourism in Panxi. The design of the hot spring health landscape is also in line with several forms of tourism products.

\section{A. Health Strategy of Hot Springs and Sports Health}

Taking a bath in hot springs and sports are activities conducive to health. Panzhihua is rich in sunshine and water resources, so we can actively promote the construction of Hongge tourism industry combining with sports training base, driving-biking landscape line, forest hiking line, and outdoor sports base. In addition to enriching the content of leisure travel industry and enhancing the quality of outdoor sports tourism of tourists and the public, we can also let visitors to eliminate physical fatigue by taking a bath in hot springs after outdoor training, riding, walking, mountaineering, and drifting and so on to form characteristic industrial chain through the combination of hot springs and sports, attract tourists, and promote consumption. We can introduce the latest international hot spring health concept, pay attention to the exploration and improvement of health function of microelement in Hongge hot spring resources, and combine with traditional medicine of Sichuan medicine, Tibetan medicine, Yi medicine to develop characteristic hot spring 
health brand. At the same time, we can provide physical examination center of high level, all kinds of sports venues, health rehabilitation center, skin beauty research institutions and medical institutions accordingly, and focus on the concentration of the health industries centering on hot springs. Combining with the construction of regional leisure project, we can make hot spring + sports health tourism products become the important engine of development of hot spring tourism industry in Panzhihua.

\section{B. Health Strategy of Hot Spring and Health Care for the Elderly}

The suitable light and heat resources and climatic conditions in Panzhihua are very beneficial for the development of health industry. Aiming at the care needs for the aged of elderly rehabilitation and health care, we can build the international elderly care service industry system taking elderly care of living, nursing for the aged, old age entertainment, and finance for the aged as the core basing on the rich fruit and vegetable resources, sound medical care institutions and hot spring resources rich in minerals and trace elements in Panzhihua. We can also take tourism real estate as the main form to develop and form community hot spring products with the function of health care for the elderly. The hot spring products in old-age community have an important effect on the improvement of the quality of real estate and life of the elderly residents in the community, of which the focus is recommending the hot springs form of health care for the elderly in the community. We should use the hot spring resources of community to enhance the quality of tourism real estate and construct corresponding hot springs leisure facilities in communities centering on hot spring to improve the living quality of the elderly and enrich the methods of elderly health care.

\section{Health Strategy of Hot Spring and Ecological Heart Nourishing}

We can make full use of the sunshine, pastoral, forest, multicultural and other resources in Panzhihua, to create a number of heart nourishing products that can release people's nature and sooth pressure. For instance, we can make full use of hot spring wastewater to build a special fruit and vegetable cultivation base and innovative the development model of the rural tourism; use national and provincial forest park to make the characteristic ecological heart nourishing products taking forest oxygen bar, painting, and music and so on as the theme. Basing on the unique natural resources in Panzhihua, we can combine the development of hot spring resources and regional tourism scenic spots (points), coordinate the routes and integrate the related derivatives like accommodation, catering, and entertainment into hot spring tourism products, to promote multi-industry elements to gather in the landscape space and build the hot spring tourism products of scenic sightseeing with characteristics of Panzhihua. On the basis of taking a bath in the hot spring, we can develop the sports and recreational facilities that can satisfy the involvement, experience and entertainment of tourists, and effectively enhance the overall attractiveness of hot spring tourism, to ease the off-season problems of hot spring business, enhance customer satisfaction, and extend the tourists' pace time.

\section{Strategies for Hot Springs and Cultural Experience Health}

Culture is the soul of tourism, and cultural needs is the fundamental driving force of tourism, so tourism process is actually a cultural experience and enjoyment. For the tourism products with heavy trend of homogeneity like hot spring tourism, the regional history and culture is the soul and characteristic of hot spring tourism development, which is the enduring vitality of hot spring tourism industry. Panxi area should integrate the immigrant culture and the third line construction culture, integrate and develop local culture represented by the Yi culture, enrich the cultural connotation of hot spring products based on spring resources and local context, and integrate calligraphic art, traditional culture, ethnic customs, and traditional handicrafts into the construction of explanation, landscape pieces, hotels, restaurants, car parks in hot springs scenic spots to create the "hot spring + culture" experience products that enable visitors to fully mobilize the sensory behavior including vision, smell, touch, sniff, and taste.

\section{DESIGN IDEAS OF HOT SPRING LANDSCAPE OF HONGGE IN PANZHIHUA}

Hot spring Landscape of Hongge in Panzhihua must express the respect for the base, the continuation of nature, the protection of environment, and the response to the regional culture. Through the design of Hot spring Landscape of Hongge in Panzhihua, we can achieve the control of the forest coverage, the attraction and service of the visitors, the construction of the overall atmosphere of the park. Attention should be paid to the principle of territoriality, the principle of cultural authenticity, the principle of uniqueness, and the principle of protection and development. Regional culture can be expressed through the landscape pieces, architecture, decoration and color.

Landscape pieces, the carrier of culture with symbolic meaning, can contrast the cultural atmosphere and its existence is the expression of culture. Regional culture and landscape pieces are closely related, since landscape pieces can reflect the culture of the landscape. Therefore, in this project design, local culture of the park can be presented through these landscape pieces.

Buildings can reflect the information of an era, which allows visitors to identify and experience the existence and evolution of a regional culture. The buildings themselves are influenced by natural factors and cultural factors. Whether in structure, shape, color or furnishings they have their own characteristics, so the buildings can reflect the regional culture of Hongge town. For example, Yi residential form will be added into design of hot spring in Hongge to show culture.

It is easy for decoration with the characteristics of regional culture to give people a deep impression. It has a strong symbolic characteristic, which is a typical cultural landscape carrier. Integrating unique folk symbols and 
patterns of the region into the landscape can express cultural themes, adding agility for the hot spring town.

People from different cultural backgrounds have different feelings for colors since the color tone is often a reflection of national cultural factors, which has the characteristic of cultural landscape. The color design of the hot spring town can reflect the unique regional culture. For instance, the colors of the Yi people are red, yellow, black and white, so local cultural characteristics can be fully reflected by using these colors as a landscape expression in the design of hot spring landscape.

\section{ANALYSIS OF LANDSCAPE DESIGN OF HOT SPRING IN HONGGE OF PANZHIHUA}

\section{A. Analysis of Landscape Design Elements of Hongge Hot Spring}

Hongge hot spring baths are surrounded by mountains and with the bridge and stone stairs as "veins", extending in all directions The whole water design rationally uses the local terrain, links the water pools together through streams, so the hot springs have both dynamic and static forms. Dynamic hot springs are set by 18 natural baths combined with the terrain, which the use of terrain gap to form the wild entertainment of natural bath. The static bath design is a huge open-air swimming pool where people can come in groups to taking baths in the pool. Some of them are terraced, or plum blossom scattered on the hillside; some takes natural grottoes as water pools to hide them in dense shade; some of them are built under a fry waterfall, showing the landscape of unity of heaven and human.

\section{B. Analysis of Landscape Design of Plant configuration in Hongge Hot Spring}

Surrounded by mountains and shades of banana trees, hot springs is located near a tropical botanical garden, with a variety of lush tropical plants, and patches of mango, lychee, camellia, and pineapple constitute a southern subtropical landscape. The plant landscape in scenic area mainly serves as the background of water pool, while there is almost no artificial plant landscape. The local native plant landscape is better used to create the primitive ecological bathing atmosphere. The choice of subtropical tree species is a major feature of the resort plant configuration. In the large green background, the corner and places near the pools are planted with deciduous tree. There are also a large number of loquat and longan trees, for visitors to experience the enjoyment of picking up after taking a bath in the pool.

\section{Analysis of the Architecture Elements of Hongge Hot Spring}

The hot spring bath area has facilities such as lotus pond pool, VIP pool, willow garden ecological pool, elephant ear tree open-air pool, wooden bucket bathroom, large open-air sunshine bath, swimming pool, and children's interactive water castle as well as the accommodation, catering, entertainment service facilities such as green spring hotel, ear tree VIP hotel, lotus pond villa, reception center, conference center, catering center, recreation center, tennis court, tea hall, and car park and so on, which are suitable for consumer groups at all levels. Currently, there are a large parking lot of one thousand square meters, 60 star standard rooms, one small sized conference room and one medium one, a restaurant that can accommodate 300 people dining at the same time in scenic area. There are a rest hall of 300 square meters, 23 various boxes in the magnificent leisure center, and in the hot spring area, there are elegant tea restaurant, modern standard swimming pool, and 18 open-air hot spring pools built along the stream. The leisure centers, mountain climbing area in primeval forest and resort hotels of star level in the scenic area have begun to take shape. Building site is selected based on the terrain, which can well coordinate the environment, and the building materials are mostly wood and stones, but the lack of construction technology makes the architecture of whole area lack features.

\section{Deficiency of Landscape Design of Hongge Hot Spring}

Of course, in the whole process of landscape design of Hongge hot springs, there are some deficiencies as follows: First, the proportion of open-air hot springs is too big, without enough indoor hot springs; Second, the hot spring bath project is too single, only two common forms including swimming and bath; Third, streamline of the space is not well distributed and that of the construction is not linked, so we can often see people walking wearing a towel in the mountains on clothes scattered around the pool, which influences the landscape; Fourth, the scenic area lack music facilities. There is almost no sound equipment in resort, so the quality of space atmosphere is poor.

\section{CONCLUSION}

The design belongs to the land, as it grows in the land instead of imposing on a land. Designers should not only design on the drawings, but also design on the site. Therefore, on the basis of the feasibility of the project, we should try to use the original terrain and landscape to make design, thus creating a more distinctive Hongge hot spring landscape that is close to the nature. Design needs to respect the ecological elements of original natural environment of the site, such as hot springs, springs, streams, ancient and famous trees, retain the original, valuable ecological elements to make use as far as possible and seize the characteristics of these elements to highlight the site characteristics. Hongge Hot Springs as a name card of Panzhihua to create a sunshine flower health city, landscape design of it should fit the concept of development and transformation of the city and adapt to the needs of urban transformation and upgrading, so only by using its own geographical, cultural, and national advantages, can it grows up quickly to become the driving force of urban development.

\section{REFERENCES}

[1] Chen Lili. A Study on the Characteristics of Resources and Product Development of Tourism in the Western Grand Canyon Scenic Area, Chengdu Univerisity of Technology, 2008(5): 34-35 
[2] Dong Yuehua. Study on Comprehensive Evaluation Method of Geological Environment of the Mine in Panxi Area Chengdu University of Technology, 2015

[3] He Qin. Discussion on the Development Mode of Yunnan Hot Spring Tourism Kunming University of Science and Technology, 2010

[4] Huang Xiang, Xu Wenxiong. The past, present and future of hot spring development model in China Planners, 2005, 21 (4): 72-74

[5] Wang Zhiwen. Design of Natural Hot Spring Resort in Julong Bay Chinese and Overseas Architecture, 2003(4)

[6] Hong Huiqun. Discussion on Design Method of Hot Spring Tourism Landscape Planning Urban studies, 2008(3): 10023-10027

[7] Song Jinglei. The denotation of hot spring--A primary Study on the Design idea and Design operation of the hot spring in Zhuhai South Architecture, 2001(2): 66-67 